\title{
Circulating Mir-497-5p as a Potential Non-Invasive Molecular Marker for Diagnosis and Prognosis in Mesothelioma
}

\author{
Majed Al Mourgi* \\ Associate Professor, Department of Surgery, Medical College, Taif University, Saudi Arabia
}

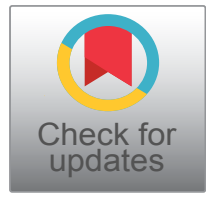

*Corresponding author: Majed Al Mourgi, Associate Professor, Department of Surgery of Surgery, Consultant Cardiothoracic Surgery, Medical College, Taif University, Saudi Arabia

\begin{abstract}
Background: Pleural mesothelioma is aggressive, surgery is the principal treatment. Mesothelioma usually diagnosed in an advanced stage. The present study was conducted to study the circulating MiR-497-5p as a possible non-invasive molecular marker for the diagnosis of mesothelioma and its role in follow-up and prognosis.

Methods: MiR-497-5p was evaluated in Mesothelioma tissues and the plasma of patients and the plasma of healthy controls. MiR-497-5p was assessed in the plasma of patients before and after surgical excision of mesothelioma.

Results: MiR-497-5p was downregulated in tumor tissues compared to normal tissues; it was also downregulated in the plasma of patients compared to the healthy controls. MiR-497-5p levels in the tissues and plasma were comparable. The plasma levels of MiR-497-5p were elevated in the patients after tumor excision. Downregulation was associated with adverse prognostic features.

Conclusions: MiR-497-5p acts as a tumor suppressor in mesothelioma. The circulating MiR-497-5p can be used as a possible non-invasive molecular marker for diagnosis and prognosis in mesothelioma patients.
\end{abstract}

\section{Keywords}

Mesothelioma, Circulating MiR-497-5p, qRT-PCR, Diagnosis

\section{Introduction}

Malignant pleural mesothelioma (MPM) is an uncommon disease, it is linked to asbestos and mineral fibers exposure, and its incidence is increasing [1]. The median survival is less than one year [2]. MPM is an aggressive tumor usually presented in an advanced stage [3].
MicroRNAs are short RNA 18-22 nucleotides that act as regulators of specific mRNA targets and involved in many biological functions and the pathogenesis of many diseases including malignancy [4]. Post-transcriptionally, they regulate the target gene negatively by either suppressing mRNA translation or enhancing the degradation of mRNAs [5]. They can function as an oncogene or as tumor suppressors by triggering one or maybe hundreds of mRNAs [6]. MicroRNAs can be secreted from all types cell to the extracellular fluid and transferred other body fluids like urine [7], blood [8], and serum [9]. About $10 \%$ of the discovered human $\mathrm{Mi}-$ croRNAs are detectable in plasma in a stabilized form [10]; this makes these small molecules ideal to act as molecular markers in cancer [11-13].

MiR-497HG human gene is located on chromosome 17p13.1, the first intron of the gene encodes MiR-497. In several types of malignant tumors, MiR-497-5p was found to be downregulated such as head and neck squamous cell carcinoma (HNSCC) [14], hepatocellular carcinoma (HCC) [15], pancreatic carcinoma [16], breast cancer [17], and colorectal carcinoma [18]. The functional role of MiR-497-5p is not fully explored in cancer, especially in MPM. To improve survival in MPM, we need to explore new molecular non-invasive markers for early diagnosis of MPM.

This study aims to study the circulating MiR-497-5p in plasma as a potential non-invasive molecular marker for early diagnosis, prognosis, and follow-up in MPM.

\section{Patients and Methods}

This study was carried out at Al Hadda Military Hos-

Citation: Al Mourgi M (2020) Circulating Mir-497-5p as a Potential Non-Invasive Molecular Marker for Diagnosis and Prognosis in Mesothelioma. Int J Cancer Clin Res 7:141. doi.org/10.23937/23783419/1410141

Accepted: August 29, 2020; Published: August 31, 2020

Copyright: (c) 2020 Al Mourgi M. This is an open-access article distributed under the terms of the Creative Commons Attribution License, which permits unrestricted use, distribution, and reproduction in any medium, provided the original author and source are credited. 
pital, Taif, SA, between June 2016 and November 2019, the study was approved by Al Hadda hospital ethical committee. The study included 30 patients ( 13 males and 17 females) with pathologically proven malignant mesothelioma. The patient's age ranged between 46 and 66 years. Twenty-two patients have good performance status. Written informed consent was obtained from all recruited patients. The performance status of the patients was assessed according to Zubord Scale [19] and patients were staged according to the latest version of the American Joint Committee of Cancer (AJCC) [20]. The patient's characteristics are presented in Table 1.

\section{Tissue and blood specimens}

All patients underwent surgical excision; biopsies were obtained from tumor tissues and nearby pleural tissues (NNT) not invaded by the tumor. Tissue specimens were stored in liquid nitrogen at $-80^{\circ} \mathrm{C}$ until analysis.

$2 \mathrm{ml}$ of venous blood was withdrawn from all patients included before surgery and 2 weeks after tumor resection. Blood samples were also obtained from 30 normal healthy individuals. Samples centrifuged at $4{ }^{\circ} \mathrm{C}$ and $1200 \mathrm{~g}$ for 10 minutes in ethylenediaminetraacetic acid tubes to separate the plasma free nucleic acids. Centrifugation was repeated to remove cells and cell debris. The supernatant plasma was collected and stored at -80

Table 1: MiR-497-5p levels in mesothelioma tissues, plasma and prognostic factors.

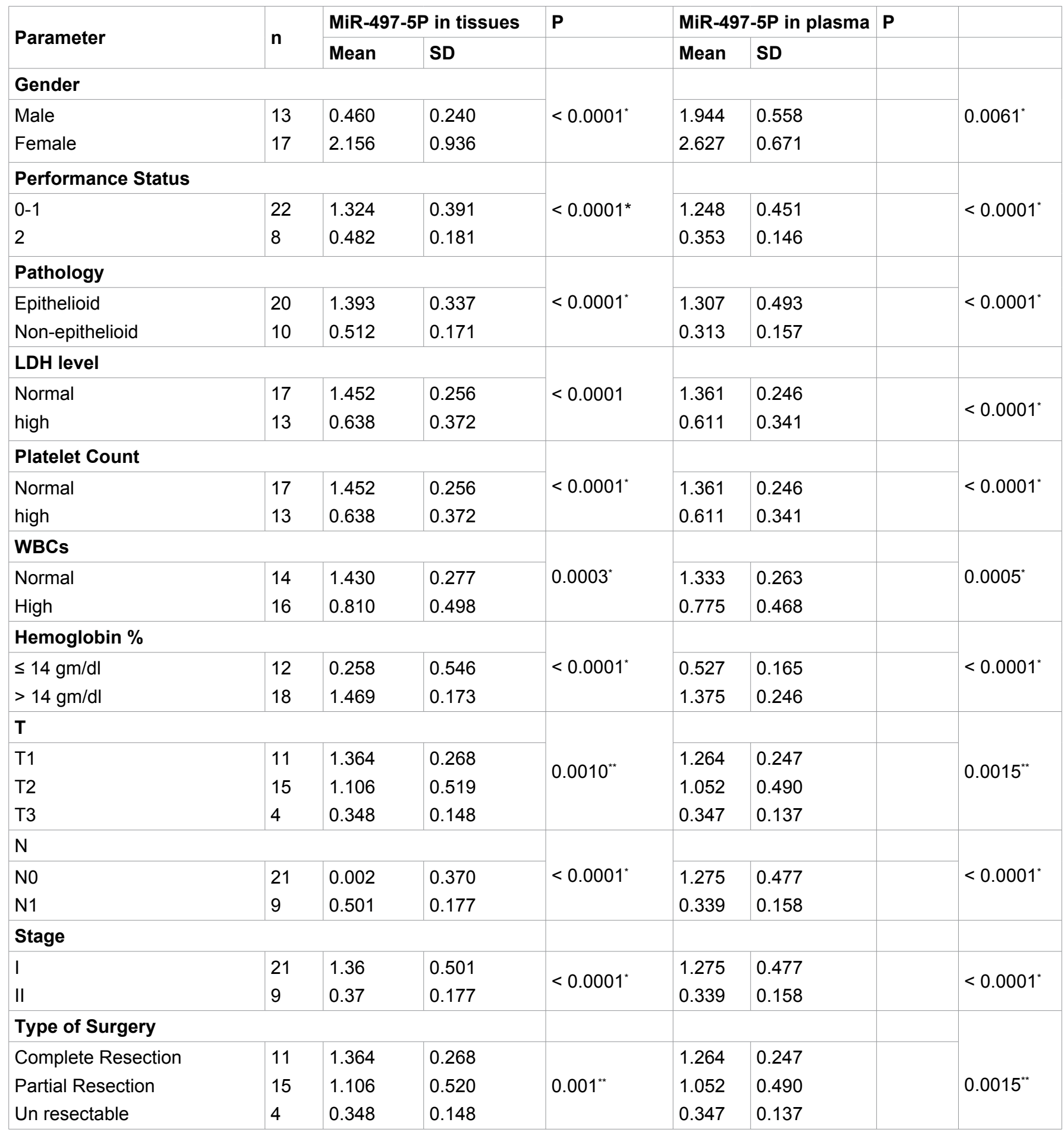


${ }^{\circ} \mathrm{C}$ in liquid nitrogen until analysis.

\section{Quantitative Real-Time-PCR of MiR-497-5p ex- pression extraction of RNA}

Total RNA was extracted from tissues and plasma by the miRNeasy Mini Kit (Qiagen, Hilden, Germany) guided by the manufacturer directions. The purified samples of RNA stored at $-81^{\circ} \mathrm{C}$ until use.
Synthesis of complementary DNA (cDNA): Reverse transcription of extracted RNA was done by iNtRON Biotechnology to synthesize cDNA according to the company guidelines.

RT-PCR: SYBR Green PCR Master Mix (Perfect Real Time; TaKaRa Biotechnology, Shiga, Japan) was used to perform the Quantitative real-time polymerase chain
A)

MiR-497-5p expression in Mesothelioma tissues and their Nearby Normal Tissues (NNT)

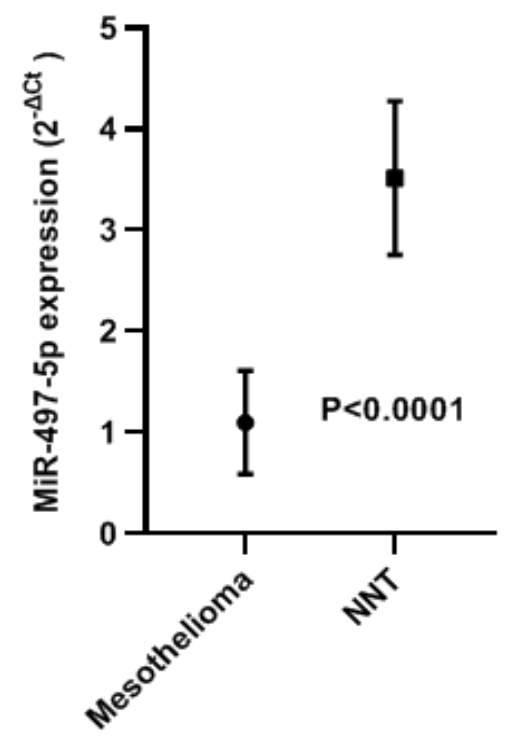

C)
B)
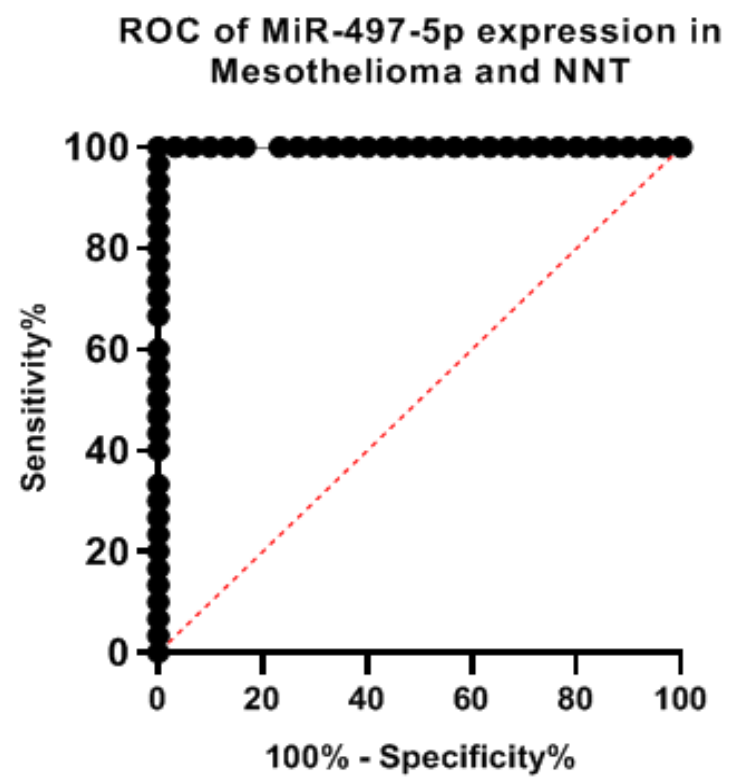

D) of Patients and the healthy controls
of
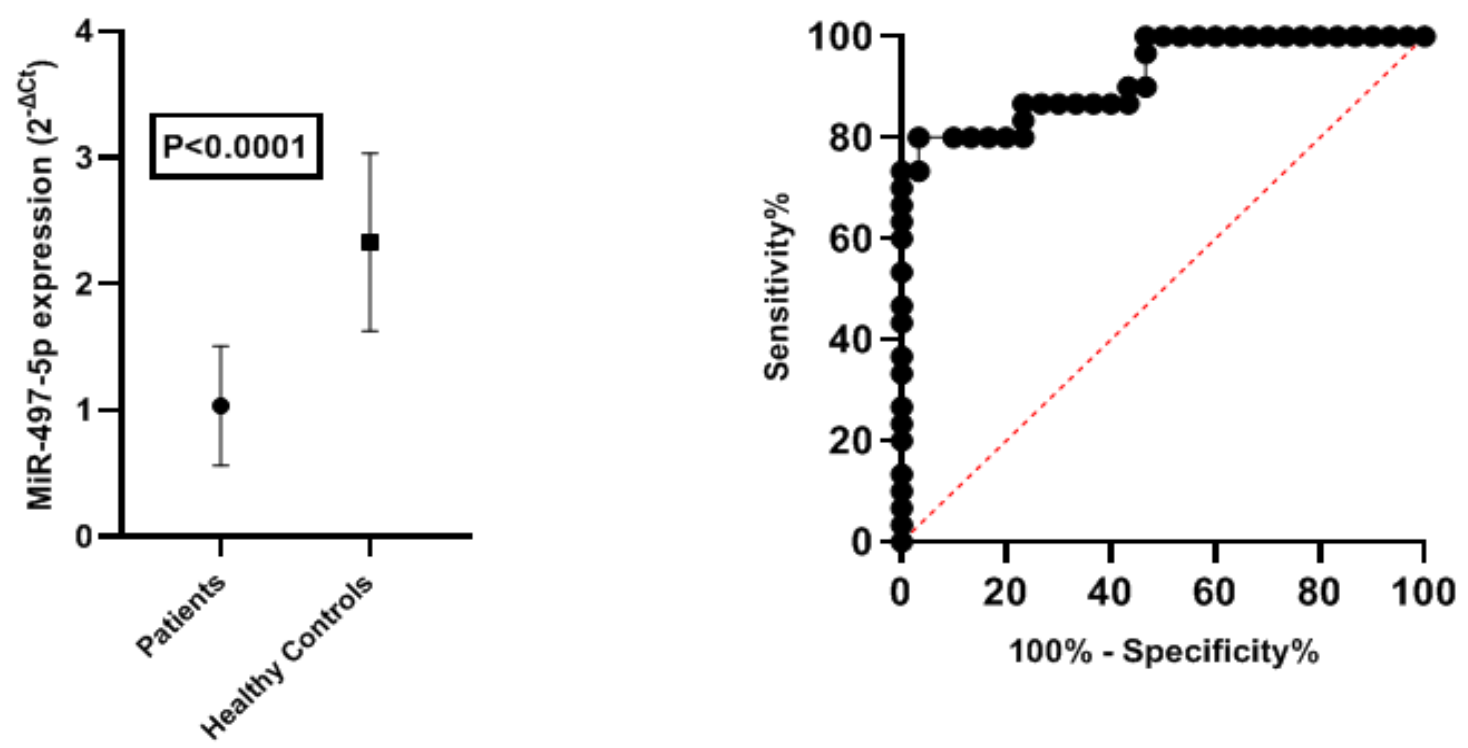

Figure 1: MiR-497-5p expression in the tissues and the plasma of mesothelioma patients and normal controls (A) Expression of MiR-497-5p in mesothelioma and their nearby normal tissues; (B) ROC curve of MiR-497-5p in Tissues; (C) Expression of MiR-497-5p in the plasma of patients and normal healthy controls and; (D) ROC curve of expression of MiR-497-5p in the plasma of patients and controls. 
reaction ( $Q$ RT-PCR) according to the company guides by the Bio-Rad CFX96 sequence detection system (BioRad Laboratories Inc.).

A $20 \mu \mathrm{l}$ of amplification mixture contains $10 \mu \mathrm{l}$ SYBR Green master mix, $5 \mu \mathrm{l} c D N A$, and $100 \mathrm{pmol} / \mu \mathrm{l}$ of the primers. The amplification was conducted by Stratagene Mx3005P-qPCR. Glyceraldehyde-3-phosphate dehydrogenase (GAPDH) was used for control. The primers sequence of primers was as follow:

GAPDH sense: 5'-GTCAACGGATTTGGTCTGTATT-3', GAPDH reverse: 5'-AGTCTTCTGGGTGGCAGTGAT-3', MiR-497-5p sense: 5'-GTCGTATCCAGTGCAGGGTCCGAGGT,

MiR-497-5p reverse: ATTCGCACTGGATACGACACCAAACA-3'.

All reactions were conducted in triplicate; MiR-497$5 p$ was normalized to GAPDH. The reactions of $q P C R$ consists of denaturation and polymerase activation for 2 minutes at $95{ }^{\circ} \mathrm{C}$ followed by denaturation for $15 \mathrm{sec}$ onds at $95{ }^{\circ} \mathrm{C}$ for 40 cycles then annealing and elongation for 1 minute at $58{ }^{\circ} \mathrm{C}$. Gene expression was quantitated by the $2^{-\Delta \mathrm{Ct}}$ method [21].

\section{Statistical analysis}

Statistical analysis was performed using version 9.4 of the SAS software package (SAS Institute, Inc.; Cary, NC, USA).

\section{Results}

\section{MiR-497-5p expression in mesothelioma tissues and Nearby Normal Tissues (NNT)}

We analyzed the expression of MiR-497-5p by qRTPCR in mesothelioma and their nearby normal tissues. We found that the MiR-497-5p level in mesothelioma ranged between 0.241 and $1.841\left(2^{-\mathrm{ACt}}\right)$ and in NNT 1.92 and 4.62. The mean \pm SD in mesothelioma was $1.1 \pm$ 0.51 and in NNT $3.5 \pm 0.7$ (Figure 1A). This difference was statistically significant $(t=14.44,<0.0001)$. A receiver operating characteristic (ROC) curve was generated to test the specificity of MiR-497-5p in tissues revealed its specificity $(A U C=1.000,95 \% \mathrm{Cl}: 1.000$ to 1.000, $P<0.0001)$, (Figure 1B).

\section{MiR-497-5p expression in the plasma of patients with mesothelioma and healthy controls}

MiR-497-5p expression was analyzed in the plasma of patients and the healthy controls, in patients the plasma level was ranged between 0.23 and 1.72 with a mean \pm SD, $1.04 \pm 0.5$ while in healthy controls it ranged between 1.3 and 3.7 with a mean \pm SD of $2.3 \pm 0.7$ (Figure $1 \mathrm{C})$. The difference was statistically significant $(\mathrm{t}=$ $8.362, \mathrm{P}<0.0001$ ). ROC curve was generated to test the specificity of MiR-497-5p by qRT-PCR in plasma of pa- tients and controls revealed $(\mathrm{AUC}=0.921,95 \% \mathrm{Cl}, 0.854$ to $0.988, \mathrm{P}<0.0001$ ) (Figure 1D).

MiR-497-5p expression in mesothelioma tissues and the plasma of patients

The expression MiR-497-5p was compared in the plasma of patients and mesothelioma tissues. In the tissues MiR-497-5p ranged between 0.24 and 1.8 with a mean \pm SD value of $1.1 \pm 0.51$. In the plasma it ranged between 0.23 and 1.7 with a mean \pm SD value of $1.03 \pm$ 0.47 (Figure 2), the difference was not statistically significant ( $t=0.501, P=0.618$ ). To test the specificity of MiR-497-5p in the plasma and tissues, we calculated the ROC curve that showed (AUC $=0.561,95 \% \mathrm{Cl}$ : 0.414 to 0.708 , P 0.416) (Figure 3).

\section{MiR-497-5p expression in the plasma of patients before and after surgical resection of the tumor}

We evaluated the MiR-497-5p in the plasma of patients with Mesothelioma before and after surgical resection of the tumor, before surgery the mean \pm SD level was $1.03 \pm 0.47$, after surgery the mean \pm SD level was $1.4 \pm 1.1$, the difference was not statistically significant $(t=1.755, P=0.086)$ (Figure 4).

\section{MiR-497-5p expression in the tissues and the plas- ma and prognostic factors}

We tested the relation between MiR-497-5p expressions in the plasma and tissues of patients with mesothelioma and clinical prognostic factors (Table 1). We found a statistically significant correlation between MiR-497-5p expressions in the plasma and tissues and all clinical prognostic factors. Increased expression of MiR-497-5p was

\section{MiR-497-5p expression in Tissues and the Plasma of Mesothelioma Patients}

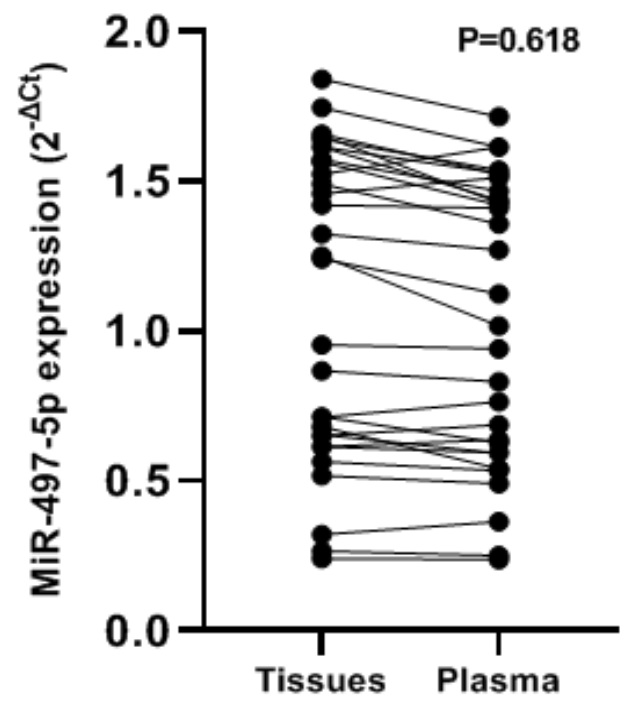

Figure 2: Expression of MiR-497-5p in the Mesothelioma tissues and the Plasma of the patients. 


\section{MiR-497-5p Plasma and Tissue of patients with Mesothelioma}

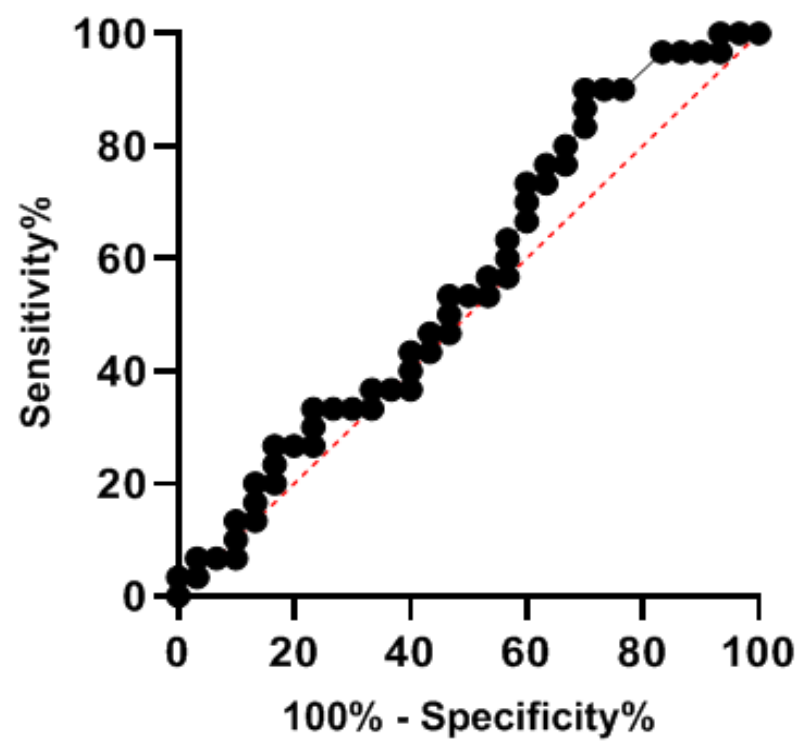

Figure 3: ROC curve for expression of MiR-497-5p in the plasma and tissues of Mesothelioma patients.

\section{MiR-497-5p expression in the Plasma of Patients Before and After Surgery}

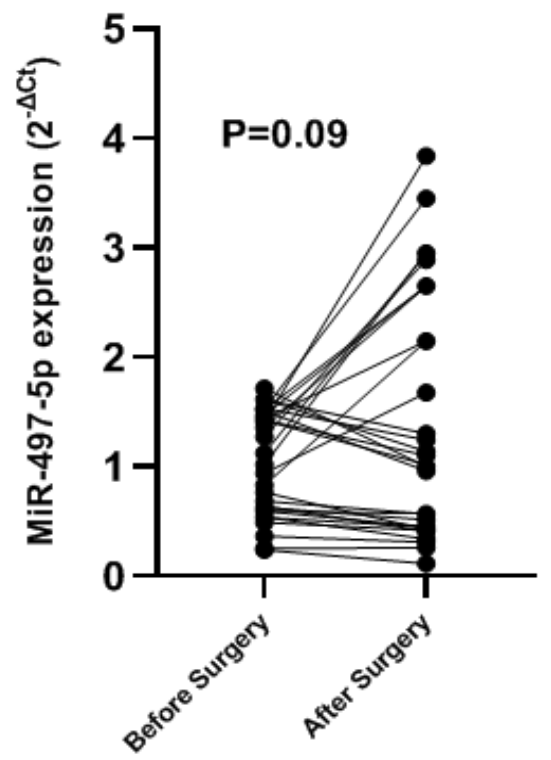

Figure 4: MiR-497-5p expressions in the plasma of patients with mesothelioma before and after surgical resection.

significantly related with female gender, good performance status of the patients, epithelioid histopathology, normal serum lactate dehydrogenase (LDH) level, normal platelets count, normal WBCs, absence of anemia, small tumor size, no lymph nodes involvement, early tumor stage, and the extent of tumor excision.

\section{Discussion}

Mesothelioma of the pleura is an aggressive tumor with short survival and poor prognosis. The main treatment of mesothelioma is surgery; surgical excision is only possible for early-stage tumors. To improve the outcome, patients should be diagnosed early. In the current study, we studied the role of MiR-497-5p in the plasma of patients with mesothelioma and as a non-invasive molecular marker for diagnosis and prognosis.

In the present study we MiR-497-5p in the tissues of mesothelioma and their nearby normal tissues not invaded by the tumor, MiR-497-5p was downregulated in mesothelioma tissues compared to normal tissue. In the plasma of patients, MiR-497-5p was also downregulated compared to the healthy controls. We compared the expression of MiR-497-5p in the plasma of patients and the malignant tissues excised from them; we found no significant difference between the plasma and tissue expression. In a study on patients with melanoma, MiR497-5p was downregulated in melanoma tissues [22]. In HCC, the levels of MiR-497-5p were also lower than the normal tissues [23]. It was also reported to be downregulated in other malignancies as HNSCC [14], breast cancer [17], colorectal carcinoma [18], in non-small cell lung cancer [24], and pancreatic cancer [16].

To validate the role of MiR-497-5p as a non-invasive molecular marker, we compared the specificity in tissues and the plasma by computing the ROC curve, MiR497-5p was specific in both tissues and plasma.

To test the role of MiR-497-5p as a potential non-invasive biomarker for follow-up of patients with mesothelioma, we measured its levels in the plasma of patients before and after surgical resection of the tumor, the plasma levels were decreased after resection but the difference was not statistically significant.

MiR-497-5p has been regarded as a sensitive biomarker with a high prognostic significance in several malignant tumors $[16,25,26]$. To our knowledge, the prognostic significance of MiR-497-5p in mesothelioma was not explored or tested. In the present study, we noted that downregulation of MiR-497-5p was significantly related to adverse prognostic features in mesothelioma such as male gender, poor performance status of the patient, non-epithelioid tumors, increased LDH level, high platelets count, increased WBCs, anemia, large tumors, lymph nodes involvement, incomplete tumor resection, and advanced tumor stage.

Our results revealed that circulating MiR-497-5p is a potential non-invasive molecular marker for diagnosis and prognosis of mesothelioma, but our results need to be confirmed in a study with a large number of patients.

\section{Highlights}

- MiR-497-5p was downregulated in tumor tissues compared to normal tissues.

- It was also downregulated in the plasma of patients compared to the healthy controls. 
- MiR-497-5p levels in the tissues and plasma were comparable.

- Patients had increased plasma levels of MiR-497-5p following surgical removal of the tumor.

- MiR-497-5p downregulation was associated with adverse prognostic features in mesothelioma.

\section{Acknowledgments}

I wish to thank professor Amal F Gharib, Professor of Medical Biochemistry and Molecular Biology, College of Applied Medical sciences, Taif University, SA.

\section{Funding}

This research did not receive any specific grant from funding agencies in the public, commercial, or not for-profit sectors.

\section{Competing Interests}

The author declares no conflict of interests.

\section{Availability of Data and Materials}

The data of the present study are available on request.

\section{References}

1. Vogelzang NJ, Rusthoven JJ, Symanowski J, Denham C Kaukel E, et al. (2003) Phase III study of pemetrexed in combination with cisplatin versus cisplatin alone in patients with malignant pleural mesothelioma. Journal of Clinical Oncology 21: 2636-2644.

2. Borasio P, Berruti A, Billé A, Lausi P, Levra MG, et al. (2008) Malignant pleural mesothelioma: clinicopathologic and survival characteristics in a consecutive series of 394 patients. European Journal of Cardio-Thoracic Surgery 33: 307-313.

3. Koyuncu A, Koksal D, Ozmen O, Demirag F, Bayiz H, et al. (2015) Prognostic factors in malignant pleural mesothelioma: A retrospective study of 60 Turkish patients. Journal of Cancer Research and Therapeutics. 11: 216.

4. Di Leva G, Garofalo M, Croce CM (2014) MicroRNAs in cancer. Annual Review of Pathology: Mechanism of Disease 9: 287-314.

5. Jamieson NB, Morran DC, Morton JP, Ali A, Dickson EJ, et al. (2012) MicroRNA molecular profiles associated with diagnosis, clinicopathologic criteria, and overall survival in patients with resectable pancreatic ductal adenocarcinoma. Clinical Cancer Research 18: 534-545.

6. Vila-Casadesús M, Vila-Navarro E, Raimondi G, Fillat C, Castells A, et al. (2018) Deciphering microRNA targets in pancreatic cancer using miRComb $\mathrm{R}$ package. Oncotarget 9: 6499.

7. Wang G, Kwan BC, Lai FM, Chow KM, Li PK, et al. (2012) Urinary miR-21, miR-29, and miR-93: novel biomarkers of fibrosis. American Journal of Nephrology 36: 412-418.

8. Agaoglu FY, Kovancilar M, Dizdar Y, Darendeliler E, Holdenrieder S, et al. (2011) Investigation of miR-21, miR-141, and miR-221 in blood circulation of patients with prostate cancer. Tumor Biology 32: 583-588.

9. Eichelser C, Flesch-Janys D, Chang-Claude J, Pantel K, Schwarzenbach H (2013) Deregulated serum concentrations of circulating cell-free microRNAs miR-17, miR-34a, miR-155, and miR-373 in human breast cancer develop- ment and progression. Clinical Chemistry 59: 1489-1496.

10. Shen J, Stass SA, Jiang F (2013) MicroRNAs as potential biomarkers in human solid tumors. Cancer Letters 329: 125-136.

11. Lindner K, Haier J, Wang Z, Watson DI, Hussey DJ, et al. (2015) Circulating microRNAs: emerging biomarkers for diagnosis and prognosis in patients with gastrointestinal cancers. Clinical Science 128: 1-5.

12. Zhang $H$, Mao F, Shen $T$, Luo Q, Ding Z, et al. (2017) Plasma miR-145, miR-20a, miR-21 and miR-223 as novel biomarkers for screening early-stage non-small cell lung cancer. Oncology Letters 13: 669-676.

13. Arab A, Karimipoor M, Irani S, Kiani A, Zeinali $S$, et al. (2017) Potential circulating miRNA signature for early detection of NSCLC. Cancer Genetics 216: 150-158.

14. Lajer CB, Garnaes E, Friis-Hansen L, Norrild B, Therkildsen $\mathrm{MH}$, et al. (2012) The role of miRNAs in human papilloma virus (HPV)-associated cancers: bridging between HPV-related head and neck cancer and cervical cancer. British Journal of Cancer 106: 1526.

15. He XX, Kuang SZ, Liao JZ, Xu CR, Chang Y, et al. (2015) The regulation of microRNA expression by DNA methylation in hepatocellular carcinoma. Molecular BioSystems 11: 532-539.

16. Xu J, Wang T, Cao Z, Huang H, Li J, et al. (2014) MiR-497 downregulation contributes to the malignancy of pancreatic cancer and associates with a poor prognosis. Oncotarget 5: 6983.

17. Lehmann U, Streichert T, Otto B, Albat C, Hasemeier B, et al. (2010) Identification of differentially expressed microRNAs in human male breast cancer. BMC Cancer 10: 109.

18. Guo ST, Jiang CC, Wang GP, Li YP, Wang CY, et al. (2013) MicroRNA-497 targets insulin-like growth factor 1 receptor and has a tumour suppressive role in human colorectal cancer. Oncogene 32: 1910.

19. West HJ, Jin JO (2015) Performance status in patients with cancer. Jama Oncology 1: 998.

20. Amin Mahul B, Frederick L Greene, Stephen B Edge, Carolyn C Compton, Jeffrey E Gershenwald, et al. (2017) The Eighth Edition AJCC Cancer Staging Manual: Continuing to build a bridge from a population-based to a more "personalized" approach to cancer staging. CA Cancer J Clin 67: 93-99.

21. Nagaraj, Nagathihalli S, M Kay Washington, Nipun B Merchant (2011) Combined blockade of Src kinase and epidermal growth factor receptor with gemcitabine overcomes STAT3-mediated resistance of inhibition of pancreatic tumor growth. Clinical Cancer Research 17: 483-493.

22. Chai L, Kang XJ, Sun ZZ, Zeng MF, Yu SR, et al. (2018) MiR-497-5p, miR-195-5p and miR-455-3p function as tumor suppressors by targeting hTERT in melanoma A375 cells. Cancer Management and Research 10: 989.

23. Zhang L, Yu Z, Xian Y, Lin X (2016) micro RNA-497 inhibits cell proliferation and induces apoptosis by targeting YAP 1 in human hepatocellular carcinoma. FEBS Open Bio 6: 155-164.

24. Huang X, Wang L, Liu W, Li F (2019) MicroRNA-497-5p inhibits proliferation and invasion of non-small cell lung cancer by regulating FGF2. Oncology Letters 17: 3425-3431.

25. Du M, Shi D, Yuan L, Li P, Chu H, et al. (2015) Circulating miR-497 and miR-663b in plasma are potential novel biomarkers for bladder cancer. Scientific Reports 5: 10437.

26. Zhao X, Zhao Z, Xu W, Hou J, Du X (2015) Down-regulation of miR-497 is associated with poor prognosis in renal cancer. International Journal of Clinical and Experimental Pathology 8: 758. 